\title{
Editorial
}

\section{Manejo farmacológico del dolor en el paciente oncológico}

Dra.D esirée Sáenz C ampos,PhD.

1. Farmacóloga clínica

ISSN 0001-6002/2004/46/3/113 Acta Médica Costarricense, $(02004$ Colegio de Médicos y Cirujanos
El dolor es un síntoma que se presenta con gran frecuencia, y universalmente se considera una señal de alerta que, en muchos casos, moviliza a los pacientes hacia la consulta médica. No obstante, el uso de analgésicos parece cada vez más cotidiano y, no en vano, el acetaminofén, con sus propiedades analgésicas y antipiréticas, resulta ser el medicamento más consumido en el país.

La multiplicidad de procesos mórbidos agudos y crónicos que cursan con dolor, posibilita sintetizar las descripciones semiológicas en patrones tipificados según evolución, origen, mecanismo, etc., los cuales permiten orientar el abordaje terapéutico individualizado con medicamentos, así como la aplicación de medidas no farmacológicas; ambas líneas de intervención (farmacológica y no farmacológica) son útiles en procura del alivio del síntoma y, a su vez, de sus manifestaciones asociadas.

En el contexto del control farmacológico del dolor, la aplicación de los principios del uso racional de medicamentos es fundamental para maximizar el beneficio farmacológico en el paciente y minimizar los riesgos derivados de la medicación y sus interacciones con productos concomitantes. Es decir, para un empleo racional de los medicamentos disponibles, procede la selección individualizada, al considerar, por una parte, la influencia de las características fisiológicas, patológicas, genéticas, étnicas, ambientales y hasta yatrogénicas de cada persona sobre la actividad de uno o varios medicamentos posibles; y, por otra, la información científica del medicamento, para verificar que atiende las necesidades del paciente según su condición en cuanto a la eficacia e intensidad analgésica documentadas, el tiempo para inicio y duración del efecto, las manifestaciones secundarias o colaterales, las interacciones con otros medicamentos o con alimentos, las vías de eliminación respecto a la condición mórbida del paciente, precauciones para su uso, etc.; y procede también la prescripción individualizada (medicamento, presentación, dosis, intervalo, instrucciones especiales, etc.).

En este sentido, la revisión que la Dra. Morales Alpízar y el Dr. Salas Herrera presentan bajo el título de Manejo farmacológico del dolor en el paciente oncológico, compila datos básicos sobre varios derivados opioides, los analgésicos antiinflamatorios no esteroidales (AINES) y algunos coadyuvantes (anticonvulsivantes, antidepresivos, bifosfonatos, etc.), con énfasis en sus mecanismos de acción y los efectos secundarios que podrían limitar su empleo. Sin embargo, omite la referencia al acetaminofén como analgésico (y antipirético), que estaría indicado para dolor leve -como los AINES- pero sin inflamación, con una dosis oral de hasta $2.4 \mathrm{~g} /$ día, cuando se usa en forma continuada. De igual manera, aunque discretamente se menciona la codeína, un opiáceo más bien empleado como antitusivo central, por ser un analgésico débil, se elude señalar la combinación acetaminofén + codeína, la cual resulta con mayor potencia analgésica que cuando se utiliza cada fármaco por separado; se encuentra disponible para uso por vía oral y se indica para alivio de dolor moderado.

La revisión también prioriza el abordaje farmacológico según la intensidad del dolor evaluado, mediante escalas validadas, y ofrece recomendaciones que podrán contribuir al mejoramiento de la atención de los miles de pacientes oncológicos con dolor. En este sentido, si el dolor de origen oncológico se puede controlar hasta en un $90 \%$, y entre el arsenal terapéutico se cuenta con medicamentos eficaces y efectivos para su control, entonces recordemos que "pocas cosas que el médico hace son más importantes que combatir el dolor" (Riola TM y Minotti V 1982). 